ZOOLOGIA 29 (5): 451-454, October, 2012

doi: $10.1590 /$ S1984-46702012000500008

\title{
A new species of Campylothorax (Collembola: Entomobryoidea: Paronellidae) from the state of Alagoas, Brazil
}

\author{
Bruno Cavalcante Bellini ${ }^{1,2} \&$ Liugo Fernando Meneses ${ }^{2}$
}

\begin{abstract}
${ }^{1}$ Centro de Biociências, Departamento de Botânica, Ecologia e Zoologia, Universidade Federal do Rio Grande do Norte. Rodovia BR 101, Lagoa Nova, Campus Universitário, 59072-970 Natal, RN, Brazil. E-mail: entobellini@gmail.com

2 Programa de Pós-graduação em Sistemática e Evolução, Centro de Biociências, Universidade Federal do Rio Grande do Norte.
\end{abstract}

\begin{abstract}
Campylothorax Schött, 1893 is a genus of Paronellidae known only from the Neotropical and Ethiopian zoogeographic provinces. Herein a new species of this genus is described and illustrated. Campylothorax mitrai sp. nov. was found in remains of Atlantic Rainforest at Rio Largo municipality, state of Alagoas, Brazil. It is the ninth described species of Campylothorax and the third recorded from Brazil. Campylothorax mitrai sp. nov. can be distinguished from other species of the genus by its peculiar dark blue color pattern associated to a unique set of setae in the labial triangle, where there is a large distinct seta ' $\mathrm{E}$ '. This condition is unique among Campylothorax species. Campylothorax mitrai sp. nov. is the first record of Collembola from Alagoas.

KEY WORDS. Atlantic Rainforest biodiversity; edaphic mesofauna; Paronellinae; Paronellini; taxonomy.
\end{abstract}

Paronellidae is one of the most familiar groups of epiedaphic Collembola in the tropics (Mari-MutT 1987, Hopkin 1997). Species of this family are characterized by long appendages (especially the antennae and furca), fourth abdominal segment elongated, smooth cylindrical dens, and mucro without setae (Christiansen \& Bellinger 1980, Bellinger et al. 1996-2012). Many forms show a very distinct color pattern, which helps to recognize the species (Hopkin 1997).

There are approximately 460 described species of Paronellidae worldwide, which represent less than $6 \%$ of all known Collembola (Hopkin 1997, Bellinger et al. 1996-2012). The family comprises two subfamilies, Paronellinae and Cyphoderinae (Soto-Adames et al. 2008). Many species of Paronellinae are found in tropical rain forests and caves, whereas most known Cyphoderinae are associated with nests of social insects in tropical and temperate latitudes (Hopkin 1997). Currently, there are 25 valid genera of Paronellinae and 12 of Cyphoderinae (SoтoADAmes et al. 2008, BELLINGER et al. 1996-2012).

In Brazil the knowledge of Paronellidae is still insufficient. Only 15 species have been recorded for the country and at least two genera, Paronella Schött, 1893 and Lepidonella Yosii, 1960 have dubious records for the country (BeLLINI \& ZeppelinI 2004, 2009, AвRAntes et al. 2010, 2012). Currently the largest genus of Paronellidae in Brazil is Trogolaphysa Mills, 1938 with five recorded species (ABRANTEs et al. 2012).

Campylothorax Schött, 1893 is a genus of Paronellinae that currently includes eight described species. This genus is known only from the Neotropical and Ethiopian zoogeographic provinces (Mitra \& Dallai 1980, Bellinger et al. 1996-2012). Species of Campylothorax are easily recognized by the presence of very long antennae, scales on the body, and a typical, strongly bent metathorax (Mitra \& Dallai 1980, Bellinger et al. 1996-2012). In Brazil, only two species have been recorded, Campylothorax cassagnaus Mitra \& Dallai, 1980 and Campylothorax schaefferi Börner, 1906. None of them has been found in northeastern Brazil until this moment (ABRANTEs et al. 2010, 2012).

Herein we describe a new species of Campylothorax from the state of Alagoas, northeastern Brazil.

\section{MATERIAL AND METHODS}

The specimens were collected with pitfall traps in remains of Atlantic Rainforest at Rio Largo municipality, state of Alagoas, Brazil, during the dry season (November 2010). They were mounted on glass slides following the procedures described by Christiansen \& Bellinger (1980).

The chaetotaxy schemes and drawings follow MARI-MutT (1987) and Mitra (1993). Type material is deposited at Museu Nacional, Universidade Federal do Rio de Janeiro (CM/MNRJ/ UFRJ).

\section{TAXONOMY}

\section{Campylothorax mitrai sp. nov.}

Figs 1-13

Total length (body and head) of the holotype $2.22 \mathrm{~mm}$. Habitus typical of Campylothorax (Figs 1 and 2). Color of fixed specimens predominantly dark blue, with some brown pigment covering ventral areas of head and body; manubrium and distal dens without pigment (Fig. 1). Brownish to hyaline rounded 

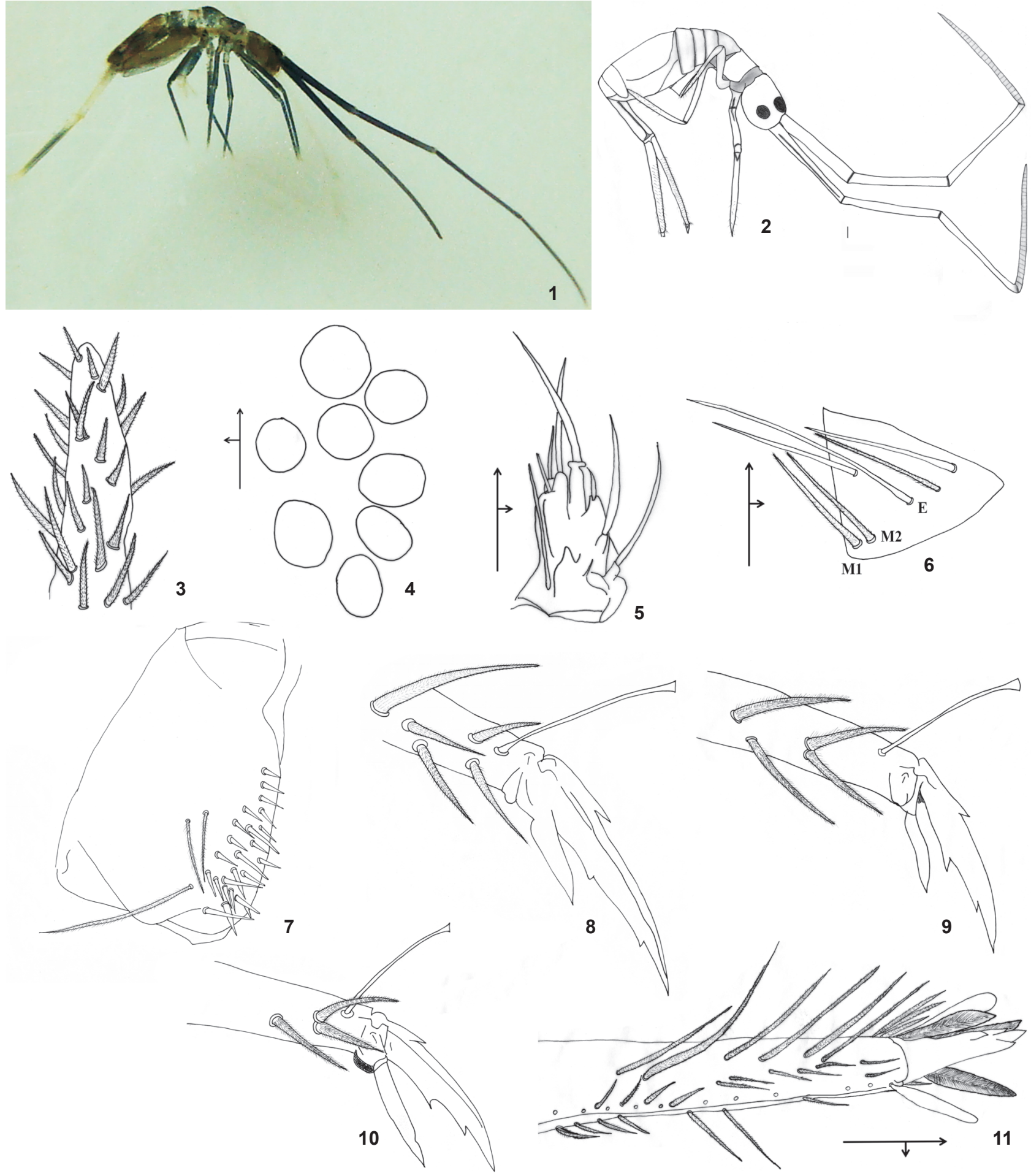

5

Figures 1-11. (1) Fixed specimen of Campylothorax mitrai sp. nov.; (2) habitus with scale; (3) apical region of the antennal segment IV; (4) left eyepatch; (5) right labial palp; (6) setae of the labial triangle (right side); (7) trochanteral organ; (8) first foot complex; (9) second foot complex; (10) third foot complex; (11) distal dens and mucro. Scale bar $=100 \mu \mathrm{m}$. 


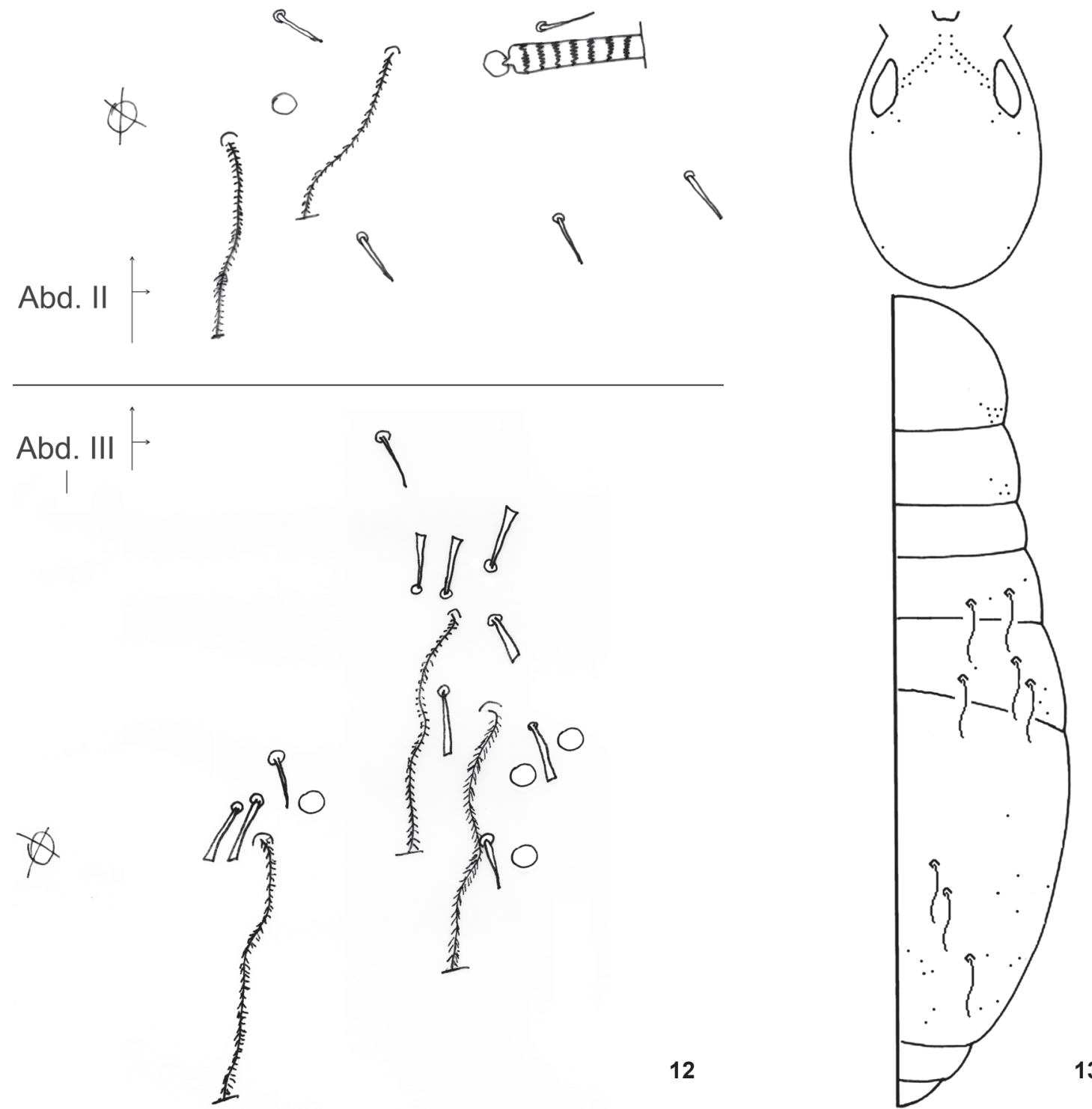

Figures 12-13. Campylothorax mitrai sp. nov., dorsal chaetotaxy of second and third abdominal segments (circles represent macrochaetae, as shown in abd. II); (13) dorsal macrochaetae distribution.

scales covering antennal segments I and II, basal halves of antennal segments III and IV, head, thorax, abdomen, legs, and furca. Collophore without scales. Antennal segment IV not annulated, without apical bulb or pin setae (Fig. 3). Eyepatches oval, $8+8$ lenses, biggest lens A and smallest lens D (Fig. 4). Prelabral and labral setae feathered. Labial palp as in figure 5. Labial triangle seta $\mathrm{r}$ absent, M1, M2 feathered and E smooth and larger than other setae (Fig. 6). Trochanteral organ as in figure 7 , with 17 to 24 short spine-like setae. All ungues with two unpaired inner teeth (Figs 8-10). Unguiculi acuminate, with smooth edges (Figs 8-10). Tenent hair capitate, smooth at edges (Figs 8-
10). Venter of manubrium with $7+7$ subapical setae. No spinelike setae on manubrium or dens. Mucro typically elongated with three apical teeth and one basal tooth (Fig. 11). Dorsal chaetotaxy of second and third abdominal segments as in figure 12. Dorsal macrochaetae distribution on head and body as in figure 13 .

Material examined. Holotype male, BraziL, Alagoas: Rio Largo (Universidade Federal de Alagoas, Centro de Ciências Agrárias), 19-XI-2010, I.P.S. Santos leg. Paratypes: 6 females and 2 males, same data as the holotype.

Etymology. The species was named after Dr. Saral Kumar Mitra, one of the most renowned specialists of the Paronellidae. 


\section{DISCUSSION}

Campylothorax mitrai sp. nov. was collected in the Federal University of Alagoas, in Rio Largo campus, within an area of preserved Atlantic Rainforest. The finding of C. mitrai sp. nov. inside a tropical forest area is consistent with data on most epiedaphic Paronellinae, which have been found in similar conditions (Mari-MutT 1987, Hopkin 1997).

The specimens were collected at the peak of the dry season, associated with soil and dead foliage coverage. The climate in Rio Largo municipality is 'As' according to Koeppen's system (Коттек et al. 2006), which means an equatorial hot climate with a distinct dry summer-wet winter precipitation regime.

Most species of Campylothorax can be distinguished by their unique color patterns (Mitra \& Dallai 1980, Mari-MutT 1987). Accordingly, C. mitrai sp. nov. can be easily separated from other Brazilian species of Campylothorax by its dark coloration (Fig. 1), which contrasts with the predominantly pale color of C. cassagnaus and C. schaefferi (BöRner 1906, Mitra \& Dallai 1980, Bellinger et al. 1996-2012). Two other species of dark pigmented Campylothorax have been recorded from the Neotropical region, Campylothorax sabanus (Wray, 1953) and Campylothorax cubanus Gruia, 1983 (Mari-MutT 1987). However, the coloration of both species does not match exactly the pattern seen in C. mitrai sp. nov. (especially in the abdominal segments) and the latter shows a very divergent chaetotaxy in the labial triangle (Fig. 6). In fact, a large distinct seta ' $E$ ' has not been recorded in any other species of the genus.

Campylothorax mitrai sp. nov. is the first record of Collembola from the state of Alagoas (ABRANTEs et al. 2010, 2012). While many efforts are being made to unveil the collembolan fauna of Brazil, this kind of data reinforces the need for more taxonomists working on the group.

\section{ACKNOWLEDGEMENTS}

We would like to thank our friend Inaura Santos for collecting the type material. The senior author is granted by $\mathrm{CNPq}$ and FAPERN.

\section{LITERATURE CITED}

Abrantes, E.A.; B.C. Bellini; A.N. Bernardo; L.H. Fernandes; M.C. Mendonça; E.P. Oliveira; G.C. Queiroz; K.D. Sautter; T.C. Silveira \& D. Zeppelini. 2010. Synthesis of Brazilian Collembola: an update to the species list. Zootaxa 2388: 1-22.
Abrantes, E.A.; B.C. Bellini; A.N. Bernardo; L.H. Fernandes; M.C. Mendonça; E.P. Oliveira; G.C. Queiroz; K.D. Sautter; T.C. Silveira \& D. Zeppelini. 2012. Errata Corrigenda and update for the "Synthesis of Brazilian Collembola: an update to the species list." ABRANTES et al. (2010), Zootaxa, 2388: 1-22. Zootaxa 3168: 1-21.

Bellinger, P.F.; K.A. Christiansen \& F. Janssens. 1996-2012. Checklist of the Collembola of the World. Available online at: http://www.collembola.org. [Accessed: February 2012].

Bellini, B.C. \& D. Zeppelini. 2004. First records of Collembola (Ellipura) from the State of Paraíba, Northeastern Brazil. Revista Brasileira de Entomologia 48 (4): 587-588.

Bellini, B.C. \& D. Zeppelini. 2009. Registros da fauna de Collembola (Arthropoda, Hexapoda) no Estado da Paraíba, Brasil. Revista Brasileira de Entomologia 53 (3): 386-390.

BöRnER, C. 1906. Das System der Collembolen nebst Beschreibung neuer Collembolen des Hamburger Naturhistorischen Museums. Mitteilungen aus den Naturhistorischen Museum in Hamburg 23: 147-188.

Christiansen, K. \& P. Bellinger. 1980. The Collembola of North America north of the Rio Grande. Grinnell, Grinnell College, 1322p.

HopkIN, S.P. 1997. Biology of the Springtails (Insecta: Collembola). Oxford, Oxford University Press, 330p.

Kottek, M.; J. Grieser; C. BeCK; B. Rudolf \& F. Rubel. 2006. World map of the Köppen-Geiger climate classification updated. Meteorologische Zeitschrift 15 (3): 259-263.

Mari-Mutt, J.A. 1987. Puerto Rican species of Paronellidae (Insecta: Collembola). Caribbean Journal of Science 23 (34): 400-416.

Mitra, S.K. 1993. Chaetotaxy, phylogeny and biogeography of Paronellinae (Collembola: Entomobryidae). Records of the Zoological Survey of India, Occasional Paper 154:1-100.

Mitra, S.K. \& R. DALLAI. 1980. Studies of the genus Campylothorax Schött, 1893 (Collembola Entomobryidae, Paronellinae) with the description of a new species from Zaire. Monitore Zoologico Italiano 13 (9): 273-321.

Soto-Adames, F.N.; J.A. Barra; K. Christiansen \& R. Jordana. 2008. Suprageneric classification of Collembola Entomobryomorpha. Annals of the Entomological Society of America 101 (3): 501-513.

Submitted: 12.III.2012; Accepted: 28.IV.2012.

Editorial responsibility: Gabriel L.F. Mejdalani 